\title{
A fundação da vida política em Maquiavel ${ }^{1}$ \\ The foundation of political life in Machiavelli
}

\author{
RODRIGO TESSER ${ }^{2}$
}

\begin{abstract}
Resumo: O homem é um ser egoísta e que tudo deseja, razão pela qual somente pode ver os outros homens como rivais à plena satisfação de seus desejos. A ideia de comunidade política, portanto, não mais aparece como um acontecimento necessário em razão da natural condição humana. Não obstante, o mundo histórico mostra que a vida coletiva eclodiu e, efetivamente, se perpetuou no tempo. Assim, o problema que nos deparamos é saber como o governante, através de suas próprias ações políticas, pode superar os obstáculos que emergem nesse mundo contingente e atingir a máxima eficácia, alterando a realidade caótica e beligerante dos homens dispersos para criar uma coletividade política livre e duradoura no tempo. A fundação da vida política, ação humana mais importante, é a que conjuga os termos fortuna e virtù, pois, para Maquiavel, o confronto entre fortuna e virtù é um cabo-de-guerra que condicionará o sucesso ou o insucesso da ação política. A fortuna é o acaso, significando a oportunidade criativa para o homem de virtù. E a virtù significa a capacidade de obter bons resultados políticos. Assim, a fundação da vida política terá, por base, a extraordinária virtù de um homem.
\end{abstract}

Palavras-chave: Maquiavel. Virtù. Fundação.

Abstract: The man is a selfish being who wishes everything, which is why he can only see other men as rivals to the full satisfaction of their desires. The idea of political community, therefore, no longer appears as a necessary event because of the human natural condition. Nevertheless, the historical world shows that collective life erupted and effectively perpetuated in time. Thus the problem we face is how the ruler, through his own political actions, can overcome the obstacles that emerge in this contingent world and achieve maximum effectiveness by changing the chaotic and belligerent reality of the scattered men to create a free political collectivity and lasting in time.The foundation of political life, most important human action, is the one that combines the wealth and ingenuity terms, therefore, to Machiavelli, the confrontation between wealth and virtù is a tug-of-war that conditions the success or failure of political action. Fortune is random, meaning the creative opportunity for the virtù of a man. And virtù means the ability to obtain good political results. Thus, the foundation of political life will be based on the extraordinary virtù of a man.

Keywords: Machiavelli. Virtù. Foundation.

\section{Introdução 3}

\footnotetext{
'Artigo extraído da Dissertação de Mestrado intitulada "Fundação, conservação e corrupção: O Ciclo da vida política em Maquiavel", disponível em <http://portalpos.unioeste.br/media/File/maria.roehrs/Rodrigo\%2oTesser.pdf>.

${ }^{2}$ Mestrando em Filosofia pelo PPGFIL da Unioeste, campus Toledo/PR. E-mail: rtesser@hotmail.com. 3Utilizamos, sempre que necessário à corroboração de nossas leituras do texto de Maquiavel, o recurso de apresentar a leitura dos comentadores, como o que foi possível, ao mesmo tempo, apresentar o estado da arte quanto ao tema tratado e obter coerência entre os textos de Maquiavel, de seus comentadores e a leitura por nós defendida neste artigo.
} 
Onde está o homem, está a sociedade (ubi homo, ibi societas 4 ). Considerando esta maneira de pensar, a condição humana pode ser concebida como decorrente da ideia de que o homem é o único zoon politikon (animal político), tal qual definido por Aristóteles na obra Política (1997, p. 146), de modo que o surgimento da vida coletiva decorreria naturalmente da sociabilidade que seria inerente à condição humana. Assim, a sociedade viveria em concórdia, e a finalidade última da polis seria o que Aristóteles chamou de "vida boa". Essa concepção teve vida longa, uma vez que preponderou até o surgimento do Renascimento 5 , principalmente em seu viés filosófico denominado Humanismo Cívico ${ }^{6}$. Este, em proporção considerável, se afastou da vida religiosa contemplativa que permeou o pensamento da Idade Média e reposicionou o homem e suas ações no centro de toda a vida política.

Maquiavel, balizado pela ideia de compreender o homem e o fenômeno político com base na verdade efetiva das coisas, verifica, pelo estudo das coisas do mundo $^{7}$, que os homens estão postos num mundo onde preponderam os sentimentos egoístas e os acontecimentos imprevisíveis e aleatórios, ou seja, num mundo onde imperam as paixões desenfreadas e a contingência da fortuna ${ }^{8}$. Assim, a verdade efetiva evidencia que os homens não seriam naturalmente ordeiros e gregários. Para Maquiavel, dá-se exatamente o contrário. O homem é um ser propenso a sentimentos ${ }^{9}$ egoístas e que tudo deseja, razão pela qual pode ver os outros homens como rivais à plena satisfação de seus interesses. Em suma, é no

\footnotetext{
${ }^{4}$ Aforismo atribuído ao jurista romano Ulpiano (17o - 228 d.C.).

${ }_{5}^{5}$ Período da História da Europa aproximadamente entre fins do século XIV e início do século XVII. Esse período foi marcado por transformações em muitas áreas da vida humana. Apesar destas transformações serem bem evidentes na cultura, sociedade, economia, política e religião, caracterizando a transição do feudalismo para o capitalismo e significando uma ruptura com as estruturas medievais, o termo é mais comumente empregado para descrever seus efeitos nas artes, na filosofia e nas ciências. Chamou-se "Renascimento" em virtude da redescoberta e revalorização das referências culturais da antiguidade clássica, que nortearam as mudanças deste período em direção a um ideal humanista e naturalista (http://m.historiadomundo.uol.com.br/idademoderna/renascimento.htm).

${ }^{6}$ Essas são as únicas características comuns do humanismo que Kristeller relata ter encontrado: "uma crença no valor do homem e das disciplinas humanísticas e no renascer do saber antigo" (KRISTELLER, Paul. Tradição Clássica e Pensamento Renascentista, p. 29).

7 A expressão "coisas do mundo" indica tudo o que existe e acontece no mundo. Engloba, portanto, a natureza e o homem. Nesse sentido, é o perecível e o passageiro. Ao indicar aquilo que é feito e vivido pelos homens, alcança o significado que hoje atribuímos à História.

${ }^{8}$ A fortuna é a expressão de tudo que é instável e inesperado. Ela possui âmbitos de atuação. O primeiro se refere à sua atuação universal, à sua influência sobre as coisas do mundo - inclusive as leis e as instituições de uma comunidade política - enquanto propulsora da história. O segundo, ao caso particular, à sua influência sobre um único homem. A fortuna, assim, consiste nas coisas externas e internas do homem (no seu próprio modo de agir). Desse modo, o homem político deve decidir sobre a melhor ação num mundo paradoxal, considerando situações constantes e situações inconstantes. Em suma, fortuna é sinônimo de acaso, de inconstância, significando para Maquiavel a oportunidade criativa para o homem de virtù.

9 Entendemos que Maquiavel não pretendeu estabelecer uma antropologia do homem em toda a sua complexidade, mas buscou estudar o modo de portar-se do homem dentro da vida política, concluindo que o seu comportamento é errático, o qual desemboca, invariavelmente, em ações mesquinhas.
} 
mundo contingente da fortuna e dos interesses egoístas de cada homem - portanto, num mundo caótico e não propenso à conciliação - que a vida política se desenlaça. Diante dessa reviravolta conceitual perpetrada por Maquiavel $^{10}$, faz-se necessário pensar em um modo de impor ordem à condição política do homem, sob pena de perecimento da própria vida política. Porém, a ideia de comunidade política não mais aparece como um acontecimento necessário em razão da natural condição humana, como posto pela filosofia clássica. Não obstante, o mundo histórico mostra que a vida coletiva foi criada e, efetivamente, se perpetuou no tempo, sobrepujando as propensões egoístas do homem e as intempéries opostas pela fortuna.

\section{$A$ virtù e a ação de fundação da vida política"1:}

É o mundo real que delimita a ação humana, de modo que é preciso ao governante $^{12}$ buscar a melhor ação dentro das possibilidades que se apresentam na situação concreta. Em verdade, como bem observa Bignotto (1991, p. 147), Maquiavel considera que a ação humana é potencialmente criadora de novas realidades para a vida humana, de modo que o problema não é somente a fortuna, mas ter o homem a virtù necessária para alterar a realidade segundo seus objetivos. A fortuna é um termo necessário no cálculo do governante na prática de suas ações políticas e, como se trata da ocasião para a ação humana, jamais se apresentará como puro fatalismo, até mesmo porque o próprio Maquiavel afirma, no capítulo XV d'O Príncipe, que a fortuna é arbitra somente de parte de nossas ações, cabendo ao homem a responsabilidade pela outra parte. Assim, ainda que não se possa impedir o evento que representa a fortuna, os seus efeitos podem ser modulados pelo homem de virtù.

Ademais, virtù, em Maquiavel, caracteriza-se como um signo valorativo que reflete, sob um aspecto, um conhecimento prático da realidade efetiva das coisas e da condição política do homem e, sob outro, um modo extraordinário de agir. A

\footnotetext{
${ }^{10}$ A teoria política de Maquiavel é fruto das instáveis condições políticas das cidades-Estado da Itália no século XV, de sua experiência prática como secretário da República de Florença, encarregado das relações com as demais cidades italianas e outros Estados, e também do seu conhecimento teórico, pois foi um grande estudioso de clássicos do pensamento político. A ruptura da teoria política de Maquiavel reside no método utilizado, que rompe com a tradição medieval, a qual expressava uma idealização religiosa da atividade política. Maquiavel, por sua vez, sugere uma política empirista, da verdade efetiva das coisas, recorrendo, muitas vezes, aos exemplos históricos da Roma Antiga para ilustrar seus pensamentos.

${ }^{11} \mathrm{~A}$ ação de fundação tratada neste artigo não se refere propriamente ao ato de criar, do nada, uma comunidade de homens. A fundação diz respeito à criação de uma nova realidade política, conforme os desígnios do fundador, onde já existe uma vida social. Portanto, o que se funda, para os fins deste artigo, é uma nova ordem política.

${ }^{12} \mathrm{O}$ governante é a pessoa, ou as pessoas, que detém poder ou autoridade sobre toda a comunidade política e deve $(\mathrm{m})$ decidir sobre sua organização e futuro. Desse modo, unifica, para fins de padronização textual, tanto o termo príncipe, utilizado por Maquiavel em O Príncipe, quanto os legisladores e líderes republicanos, os quais Maquiavel chega a chamar, nos Discursos, de "príncipes das repúblicas" (D, I, 12 e II, 2).
} 
virtù, desvinculada de qualquer significação moral ou religiosa, revela um conjunto de estratégias e técnicas que o governante deve dominar para que mantenha seu poder e a ordem na comunidade política. Assim, a virtù é um conjunto de qualidades que possibilitam o êxito da ação política e desdobra-se, segundo Ames (2002, p. 138), em inteligência para calcular a melhor ação; sentido de realidade; rápida compreensão do que cada situação possibilita e capacidade de adotar medidas extraordinárias. Deve-se perceber, no entanto, que Maquiavel não nos afirma que o homem de virtù se opõe à fortuna propriamente, já que seria impossível diante do seu caráter de inevitabilidade, e prova disso é que nada pode o homem fazer, por exemplo, para deter a precipitação atmosférica. Por óbvio, está além das forças humanas determinar, com exatidão, quando este fenômeno natural irá acontecer e impedi-lo. No entanto, o governante deve utilizar seu conhecimento da história e das coisas do mundo para, em conjunto com técnicas e estratégias, submeter os efeitos da fortuna aos seus desígnios. É justamente o que Maquiavel pretende mostrar com a sua metáfora da enchente, apresentada no capítulo XXV de O Príncipe (2013). Inicialmente, compara a fortuna a um rio furioso, que arrasa tudo por onde perpassa. A seguir, afirma que os homens, nos tempos de calmaria, podem construir diques e barragens para evitar novos prejuízos em caso de nova enchente. Desse modo, o governante forja sua virtù na luta diária contra a adversidade do mundo e dos homens, na sua ação prática sobre um mundo em que, constantemente, o exercício do poder é posto à prova. É sob esse signo que Maquiavel enfatiza que o destino dos homens é definido pelas suas ações e não pela fortuna.

A constatação da virtù de um governante se dá somente com o resultado prático de suas ações no dia-a-dia do mundo político. Assim, uma ação pode expressar virtù em uma sociedade de determinada época e local. No entanto, a mesma ação pode não conter virtù em uma sociedade de outra época ou local. Ou seja, a virtù se refere à disposição de realizar o que determina a necessidade política, seja uma ação boa ou má pela ótica moral ou religiosa. A virtù, desse modo, não mais reflete, tão-somente, a boa educação, nobres sentimentos ou a observância de dogmas religiosos. Almeja-se, na verdade, os meios políticos efetivos que permitam a manutenção da vida política. Senellart (2006, p. 240-241) afirma que "a realidade não é mais percebida como o espaço harmonioso onde se manifestam as perfeições singulares, mas como o palco de uma batalha permanente". Assim, para este autor, a virtù "não designa mais uma forma superior de qualificação ética, mas a atitude criativa, própria do homem de Estado, contrária à passividade dos súditos". E prossegue afirmando que "sendo a conservação do stato o fim da virtù, não implica mais o emprego de qualidades constantes, mas uma extrema mobilidade de espírito". O autor arremata afirmando que "não há norma universal da virtù, porque seu domínio é aquele, instável, em perpétua mutação, das coisas submetidas ao movimento do tempo" (SENELLART, 2006, p. 240-241). 
O certo é que toda ação enfrentará a indeterminação do mundo histórico, a condição errática das ações humanas e o desconhecimento do próprio caminho a ser percorrido. Significa dizer que toda ação é a criação de uma nova realidade política. Para Hebeche (1988, p. 62), a virtù é o bloqueio das ameaças da fortuna e a utilização de suas possibilidades criativas. Nesse sentido, pode-se afirmar que Maquiavel entende a virtù como a capacidade de perceber a lógica, o significado e o valor das coisas e, assim, agir no sentido de modelar a realidade conforme os fins do governante. Entretanto, a virtù não é só uma simples oposição às forças da fortuna e à propensão egoísta do homem. É uma oposição consciente, baseada em conhecimentos, técnicas e estratégias que, se bem utilizadas, resultarão na melhor ação diante das possibilidades existentes no mundo político. Segundo Ames (2002, p. 136), a virtù é o conhecimento prático da história e da condição política do homem utilizada para melhor apreender a situação presente e agir da melhor maneira possível. Assim, a concretização da virtù não prescinde do domínio de certas técnicas e estratégias. Nesse aspecto, esclarece Ames (2014, p. 89-90) que

A ação que Maquiavel tem em vista não é a instrumental, como a ação técnica que transforma a natureza, e sim a ação estratégica: ação que se dirige a outros homens que, como atores políticos, podem oferecer resistência ou cooperar com a ação proposta. Esta ação é o contingente e o incerto por excelência, pois se defronta com a fortuna: o imprevisível e aleatório que interfere no bom êxito das ações. É isso que torna necessária a virtù (complexo de aptidões que permite aos homens destacar-se e impor às coisas o rumo por eles decidido), não para controlar a fortuna (não há como controlar o imprevisível e o aleatório), mas para encontrar desde dentro da própria ação alguma lógica, alguma maneira de levá-la a bom termo com procedimentos empiricamente eficazes e possíveis (viáveis).

O mundo, como já dito, é contingente, aleatório e nada pode o homem fazer para deter o seu movimento. No entanto, até mesmo desse movimento aleatório do mundo podem ser extraídos bons efeitos pelo homem que detém o conhecimento das coisas do mundo e que agir com audácia e precisão. Sobre isso, é válido salientar que se o mundo muda aleatoriamente o seu modo de se expressar, o homem deverá possuir a flexibilidade para acompanhar as mudanças do mundo. Essa é a ideia exposta por Maquiavel no capítulo XXV de O Príncipe (2013) e no capítulo IX, do livro 3, dos Discursos (2007), cujo título é "De como é preciso variar com os tempos quem quiser sempre ter boa fortuna”, demonstrando exatamente a necessidade de flexibilidade que deve acompanhar o espírito do governante. Essa perspectiva revela que a virtù não está relacionada somente ao embate com fatores externos ao homem. Em grande parte, reporta-se à natureza do próprio homem que não se adapta facilmente à contingência do mundo e ao fluxo do tempo. Essa é a grande dificuldade do governante: alterar seu modo de agir conforme se alteram os tempos. E tal dificuldade ocorre "[...], seja por incapacidade de apartar-se daquilo a que a sua 
natureza o inclina, seja porque, havendo sempre prosperado ao seguir por uma determinada trilha, não pode persuadir-se a desviar-se dela" ( $O$ Príncipe, XXV). A ausência de virtù, assim, está diretamente ligada a uma característica individual do homem, à sua intransigência no modo de proceder e perceber a alteração dos tempos. Desse modo, a virtù não se revela somente na contraposição subjetiva do homem ao momento objetivo da fortuna. A fortuna está, como já mencionado, nas coisas do mundo e, portanto, no próprio homem, ou seja, até mesmo na sua subjetividade, com suas dúvidas e deficiências. Segundo Hebeche (1988, p. 65), a virtù é também o combate às fraquezas do ser humano. Assim, Maquiavel confere à virtù a qualidade da flexibilidade e adaptação diante dos acontecimentos com o propósito de encontrar a medida mais adequada diante da ocasião que o mundo apresenta. A chave do sucesso de um governo consiste em reconhecer a força das circunstâncias, aceitar o que determina a necessidade e adaptar sua conduta aos tempos (SKINNER, 2012, p. 56).

Esse modo de pensar decorre da filosofia humanista, que recolocou o homem no centro do universo, conferindo ao seu livre-arbítrio um valor até então ignorado na filosofia cristã-medieval. E não poderia ser diferente. Somente a revalorização do livre arbítrio poderia fundamentar uma nova teoria da ação, desvinculada e despreocupada com juízos teológicos e morais, eis que a ação ocorre no mundo dos homens e, nele, devem surtir os seus efeitos. Para Maquiavel, a ação política pertence à categoria das ações mais importantes que o homem pode praticar. Por esse motivo, a ação política deve buscar o mais alto nível de perfeição e eficácia, contribuindo decisivamente para a fundação da vida política. A fundação de uma comunidade é a mais nobre das ações políticas, pois é a criação da vida política no mundo desordenado da fortuna e da condição egoísta do homem. Trata-se da substituição do individual pelo mundo político coletivo. É pela grandiosidade do desafio que Lefort (1972, p. 366) afirma que "sem dúvida, a fundação do Estado é o empreendimento mais nobre, o mais perigoso e o mais glorioso que é oferecido à reflexão do teórico, pois ele confere a um povo sua identidade política e requer do príncipe que se joga nela a mais alta virtù". Trata-se, segundo Duvernoy (1974, p. 98), da criação, pelas mãos de um homem excepcional, de um novo mundo político, com novas ordens, leis e objetivos.

Os homens, sem uma vida política bem ordenada, são como uma massa disforme e que, para bem funcionar, devem ser organizados e direcionados à vida coletiva. Cabe ao fundador, portanto, impor a melhor forma aos homens desordenados que encontra no caminho que trilha para a fundação de uma nova vida política. Assim, Maquiavel introduz, em sua linguagem da fundação, a correlação matéria-forma, conhecida desde a antiguidade clássica pelas obras de 
Aristóteles $^{13}$. No entanto, Maquiavel não adota o significado e a extensão da concepção derivada da terminologia aristotélica. Para Aristóteles, a forma é eterna e determina as mudanças da matéria, ou seja, a forma tem primazia sobre a matéria. Em sentido oposto, Maquiavel afirma que a forma deve se adaptar à matéria ( $O$ Príncipe, XXVI). Isso significa que os homens se apresentam como uma matéria disforme, sem qualquer organização, e somente a imposição de uma nova ordem, de uma nova forma, poderá lhes conduzir à vida política tal qual pensada pelo fundador. A correlação matéria-forma é utilizada em várias outras passagens dos Discursos e de O Príncipe. Maquiavel afirma no capítulo VI de O Príncipe, ao tratar dos homens que se tornaram príncipes por sua própria virtù, que os homens devem ser encarados como a matéria em que o fundador deverá introduzir a forma mais adequada às suas pretensões: “[...] não podemos concluir que da fortuna eles hajam recebido mais do que a ocasião que a materialidade de suas vidas ofereceu-lhes de poderem nela mesma introduzir a forma que lhes parecida justa.”. No capítulo XXVI de $O$ Príncipe, Maquiavel se utiliza dessa relação, por duas vezes, para indicar a ação fundadora de $O$ Príncipe. Na primeira afirma que "considerando, pois, todas as coisas discutidas acima, e pensando comigo mesmo se na Itália do presente os tempos são propícios para honrar um novo príncipe, e se há matéria que de ocasião para que alguém prudente e virtuoso pudesse aí introduzir a forma [...]”. E na segunda, afirma que "na Itália não falta matéria para introduzir qualquer forma de poder”. Ames (2014, p. 98), analisando a correlação matéria-forma utilizada por Maquiavel para tratar da fundação da vida comum, afirma:

Os homens, em sua existência dispersa, são a "matéria" na qual o príncipe introduz a "forma", isto é, um modo de vida organizado com ordenamentos jurídico-políticos, caracterizada por Maquiavel como Estado. Desse modo, pode-se dizer que o príncipe é construtor de um mundo: ali onde existia somente caos, universo humano disperso, rivalidade de paixões, ele cria um universo regrado. Neste movimento, o príncipe faz do próprio homem sua matéria.

O mérito do fundador, portanto, está em dar uma forma conveniente para a matéria (os homens), institucionalizando a nova ordem política.

É possível extrair desse ato de fundação da vida política, tal qual teorizado por Maquiavel em $O$ Príncipe e nos Discursos, alguns elementos essenciais. Um desses elementos, ou regra geral como afirma Maquiavel, é o de que a fundação é um ato solitário, realizado por um só homem:

E deve-se tomar isto por uma regra geral: que nunca, ou raramente, ocorre que alguma república ou reino seja desde seu princípio bem

\footnotetext{
${ }^{13 E t i m o l o g i a ~ a r i s t o t e ́ l i c a, ~ c u j o ~ s i g n i f i c a d o ~ v e m ~ d a ~ s e g u i n t e ~ c l a s s i f i c a c ̧ a ̃ o, ~ h y l e ́ ~ e m ~ g r e g o ~ s i g n i f i c a ~}$ matéria, morphé também em grego que dizer forma. Toda realidade para Aristóteles fundamenta-se em dois princípios, matéria e forma.
} 
ordenado ou reformado inteiramente com ordenações diferentes das antigas, se não é ordenado por uma só pessoa (Discursos, I, 9).

O motivo dessa exigência se deve ao fato de que "[...] a multidão não é capaz de ordenar uma coisa, porque não conhece o bem que há nela devido às diferentes opiniões que têm entre si” (Discursos, I, 9). Assim, Maquiavel entende que somente um único homem pode ser o encarregado da tarefa de criar uma nova realidade política, pois, segundo Ames (2011, p. 30), "Não há ação política mais eficaz do que aquela que condensa, numa só vontade, a vontade e o poder de muitos".

A exigência de que o fundador realize sozinho a extraordinária obra de criação de uma nova ordem política não é, porém, uma autorização ao poder despótico. Ao contrário, para Maquiavel o fundador tudo pode para efetivamente dar vida a uma comunidade política organizada, desde que "[...] tenha a intenção de querer favorecer não a si mesmo, mas o bem comum, não a sua própria descendência, mas a pátria comum" (Discursos, I ,9).

Outro elemento do ato de fundação é que se faz necessário o uso da força e da violência. Segundo Ames (2011, p. 32), deve-se recorrer a "[...] procedimentos extraordinários para fundar novas ordens institucionais ...”. E o melhor exemplo de tal situação, para Maquiavel, encontra-se na fundação de Roma, mas precisamente no exato momento em que Rômulo assassina seu irmão Remo. Maquiavel ressalta a importância desse momento afastando-se das interpretações que lhe são anteriores $^{14}$, ou seja, desvinculando-se de concepções morais ou meramente históricas, para reconhecer "[...] no homicídio o ato fundador enquanto tal, único capaz de fazer emergir sujeitos políticos" (AMES, 2011, p. 31). Exemplo eloquente dessa afirmação encontramos no comentário que o próprio Maquiavel faz do fratricídio cometido por Rômulo. Segundo ele, é necessário que "[...] se considere o fim que o levou a cometer o homicídio" (Discursos I, 9). Ou seja, devemos compreender que Rômulo foi violento "[...] para reconciliar (racconciare) e não para destruir (guastare)", como mostra o fato de haver "[...] ordenado um Senado para servir-lhe de conselho" (Discursos, I, 9). Não é por outro motivo que a morte de Remo, conforme Ames (2011, p. 32):

representa um sacrifício fundador de extraordinária significação atribuindo à origem de uma instituição ou de uma ordem política um caráter sagrado e inviolável, como se a morte que inaugura tais instituições simbolizasse a pena que acarreta sua transgressão. De outro lado, essa prova violenta de um extraordinário e absoluto poder marca a transformação do poder pessoal em institucional: a

\footnotetext{
${ }^{14}$ Ames (2011, 32) esclarece que as intepretações anteriores, "seja cristã, seja pagã, centra-se na relação meio-fim: ou condena o fratricídio como injustificável, independente do fim proporcionado; ou justifica a morte violenta de Remo por Rômulo, em nome da grandeza do resultado (a fundação de Roma)."
} 
transição do poder e autoridade de "um só" homem para o poder daquilo que somente "muitos" poderão conservar.

É preciso considerar, portanto, que a origem da vida política pode se dar por meio do uso da força e da violência, pois, para se atingir o objetivo são toleradas tais atitudes, mesmo que extraordinárias, comportando, inclusive, o assassinato (até mesmo do próprio irmão do fundador). Assim, apesar da necessidade de demonstrar elevada virtù, os fundadores de novas comunidades políticas não podem dispensar o uso da força. São insensatos os indivíduos que, como o líder religioso Girolamo Savonarola, se fiam na prece e esquecem que Moisés estabeleceu seu reino pela força (AMES, 2002, p. 185). Uma das maiores dificuldades da fundação, segundo Maquiavel, reside na necessidade de introduzirem-se novas ordenações e leis, as quais serão os alicerces da comunidade recém-conquistada. No entanto, o príncipe conquistador, ao introduzir a nova ordem, "terá por inimigos todos os que da velha ordem extraíam privilégios e por tímidos defensores todos os que das vantagens da nova ordem poderiam usufruir." (O Príncipe, VI). Desse modo, o príncipe deve valerse da imposição de sua própria força, pois os príncipes que se apoiam na força de terceiros "sempre terminam mal e não chegam a lugar algum." (O Príncipe, VI). Em sua Legação ao Duque Valentino (RIDOLFI, p. 71-84) e no capítulo VII de $O$ Príncipe, Maquiavel exalta as qualidades de César Bórgia acerca da conquista da Romanha, pois a encontrou sem leis e sem ordem, de modo que lhe foi necessário pacificar o território. Para realizar essa tarefa, Bórgia nomeou governador Remirro da Orco, segundo Maquiavel, "homem cruel e expedito" (O Príncipe, VII). Portanto, com a finalidade de ordenar o Estado recém-conquistado, Bórgia, conscientemente, utilizou-se da força. Uma vez obtida a pacificação social, percebeu que a continuidade da crueldade já não mais se fazia necessária e poderia até mesmo trazer-lhe o ódio da população, de modo que ordenou a morte do governador por ele próprio nomeado. No fato histórico relatado, percebe-se que Remirro é, por natureza, cruel e somente por meio da crueldade sabe agir. Bórgia, ao determinar a morte de Remirro, não adquiriu a fama de cruel, pois sua crueldade foi utilizada somente no exato momento em que a circunstâncias exigiram uma ação cruel. A ação de Bórgia, para a população sob o jugo de Remirro, foi benevolente com as aspirações do povo. Assim, por meio da crueldade bem empregada, Bórgia tornou-se o benfeitor daquele povo, obtendo seu consentimento para a manutenção de sua posição de governante. Para Ames (2002, p. 186):

esse exemplo ensina que o emprego da força, mesmo na sua forma mais cruel e violenta, tem como o seu outro lado a busca do consentimento popular. É precisamente este último aspecto que parece decisivo: ao mostrar, com a análise da ação política de Cesar Bórgia, que a fundação é, na sua essência, um gesto solitário, Maquiavel ensina que ele somente será eficaz se escapar da pura lógica da força. Quer dizer, é preciso que desde o começo os homens possam acreditar na grandeza dos gestos do príncipe para 
que ele próprio possa criar uma imagem positiva de sua obra de modo a torná-la segura e duradoura.

No caso da fundação de um principado, de figura inicial de mero vencedor de uma guerra, que impõe pela força a sua vontade - ou seja, onde a dimensão política anterior foi extinta -, surge a figura do fundador, que cria uma nova realidade política a partir do caos que decorre de toda guerra. Em suma, a realidade destruída pela guerra é recriada, conforme os novos valores do fundador. É necessário, portanto, distinguir a conquista - momento de pura negatividade - da fundação - momento positivo, de criação da vida política. Na fundação, o povo é a matéria que se deve dar uma forma adequada, ou seja, que se deve organizar para criar e conservar a vida política. Assim, a fundação é a combinação do gesto de força do príncipe durante a conquista e da esperança do povo nas novas leis e instituições (BIGNOTTO, 2005, p. 132). Em verdade, não se trata de pura e simples imposição de força física por parte do príncipe, cujo momento pertinente se processa durante o ato de conquista, pois, em seguida, deverá introduzir novas instituições e leis, de modo que o príncipe deverá considerar que, necessariamente, coexistirá com indivíduos que domina, ou seja, sua autoridade sobre o povo deverá ser mantida diariamente, o que não é possível pela imposição desenfreada e perpétua da força bruta. A partir disso, a força física, imposta no ato de conquista, dever ser substituída pela força da lei e das instituições (nova ordem política). Assim, pode-se afirmar que a violência contida na origem da fundação deve ser passageira, utilizada somente enquanto necessária, e substituída o mais breve possível pela força da lei e das instituições, de modo que a ordenação da vida política exaure e transcende a violência da conquista. Segundo Ames (2011, p. 36):

não há, desde o Estado, instituições nem ordenamentos ou leis que não se fundem e se estabeleçam sem um grau de maior ou menor violência, proporcional à violência que visam a suprimir. Isso significa que as ordens e instituições representam sempre a abolição da violência fundadora, a qual foi necessária para eliminar e deixar à margem dela, "fora da lei", toda outra possível violência; em outras palavras, toda lei, ordem e instituição significa que, fora delas, tudo é crime.

Assim, a fundação não prescinde do uso da força e da violência em seu momento originário. Porém, essa violência somente se justifica se, desde logo, for superada pela instituição de leis e pelos ordenamentos que beneficiem a todos, ou seja, desde que o fundador não utilize da violência apenas para manter o seu poder arbitrário sobre os demais homens. Dessa forma, é preciso que a violência deixe de ser $o$ ato que apenas subjuga os demais homens e passe a ser o ato que cria a dimensão política, ou seja, o ambiente em que a discussão política não mais se resolve pelo uso arbitrário da força, mas por meio do estabelecimento de leis e ordenações impessoais a serem observadas por todos. 
Outro elemento do ato fundador foi apontada por J. F. Duvernoy (1974, p. 102/103), no sentido de que - em que pese admitir que a força é uma das características da instauração da vida política - a ordem política pode ser obra da vontade dos indivíduos que instituem e limitam os poderes do Estado e que, sendo obra da vontade, inclusive pode ser revogada por um novo consenso. Assim, existiria a possibilidade de que a vida política possa ser fundada consensualmente, ou seja, teria como característica o acordo entre as vontades dos indivíduos: o contrato. A leitura do capítulo 2 do Livro I dos Discursos, o qual trata da origem da vida coletiva em razão da segurança que se poderia obter pela eleição de uma autoridade comum, mais precisamente na passagem em que Maquiavel afirma que, para evitar as injúrias, "os homens se determinaram fazer leis e a ordenar punições para quem as contrariasse. Tal foi a origem da justiça.", é de onde Duvernoy retira sua concepção de que Maquiavel teria estabelecido o contrato como uma das possibilidades da origem da vida política, pois as vontades individuais realizaram um acordo - eleição de uma autoridade — cujo objetivo é a salvaguarda dos próprios contraentes. Para Duvernoy (1974, p. 102/103), três consequências importantes decorrem dessa concepção de que o contrato pode estar na origem da vida coletiva: a primeira, no sentido de que "a ordem política não é transcendente com relação às vontades individuais porque ela é obra destas vontades. [...]. O Estado não é, então, outra coisa que o produto consciente de uma coletividade de homens...". A segunda, no sentido de que "[...] O objetivo do Estado é evidentemente definido, não com relação à existência do próprio Estado, mas aos interesses e necessidades dos contratantes.”. Por fim, a terceira consequência é a de que "o contrato é revogável se o objetivo, pelo qual ele foi instituído se acha desviado, falsificado, ou se perdeu seu interesse para os contratantes.” Assim, segundo Duvernoy, umas das linguagens utilizadas por Maquiavel para tratar da fundação da vida política comportaria a origem contratual.

\section{Considerações finais}

A obra política de Maquiavel consiste em uma reflexão sobre a ação humana enquanto instrumento de fundação e conservação de uma comunidade política. Por essa razão, nos pareceu pertinente extrair dela, com apoio em textos de seus comentadores, o entendimento de como a vida política tem sua origem. A questão passa por descobrir como e por quem a vida política pode ser fundada. A ação de fundação é a praticada no mundo histórico, ou seja, em determinada época e perante certos homens. Por isso, ela deve enfrentar a propensão dos homens ao egoísmo e considerar que o mundo é contingente. Diante dessas situações, faz-se necessário buscar uma resposta ao problema da fundação da vida política.

Concluímos que a comunidade política somente pode ser criada por um homem capaz de superar a fortuna e a propensão egoísta dos homens, criando as condições necessárias ao estabelecimento da vida política. Nesse momento, 
deparamo-nos com a questão que envolve saber quais as qualidades que o homem que pretende fundar a vida política deve apresentar para superar os obstáculos que se apresentam a ele em sua empreitada. Não há dúvida de que o desafio que se impõe é prodigioso. E somente poderá ser superado, da perspectiva de Maquiavel, por um homem excepcional que se poste acima do egoísmo próprio da condição política do homem e imponha a todos, pela razão ou pela força, a vida política organizada. Somente um homem com excepcionais qualidades poderá fazer frente ao imponderável do mundo e inscrever na história suas realizações de forma perene, em favor da fundação da comunidade política. Desse modo, para obter sucesso em sua jornada, esse homem deve possuir características próprias suficientes para demonstrar sensibilidade às alterações do tempo e, assim, confrontar as incertezas da fortuna, fazendo de suas circunstâncias voláteis uma verdadeira ocasião para a ação política bem sucedida. Tais qualidades, concluímos, são sintetizadas por Maquiavel no conceito de virtù

Em decorrência da análise que fizemos, podemos concluir que a virtù pode ser considerada como a qualidade que o homem deve possuir de se adequar ao contexto em que sua ação se faz necessária. Não é, portanto, um conjunto de virtudes fixas e já familiares, pois a ação de virtù se revela de acordo com as circunstâncias do espaço-tempo. Assim, a derradeira e inafastável conclusão é a de que a virtú de um homem excepcional é o meio mais adequado para fundar a vida política.

\section{Referências}

MAQUIAVEL, Nicolau. Discursos sobre a primeira década de Tito Lívio. Tradução MF. São Paulo: Martins Fontes, 2007.

. O Príncipe. Tradução de Antonio Caruccio-Caporale. Porto Alegre: L\&PM, 2013.

AMES, José Luiz. Maquiavel: a lógica da ação política. Cascavel: Edunioeste, 2002

. Reflexões sobre Maquiavel/Rafael Salatini \& Marcos Del Roio (organizadores). -

Marília: Oficina Universitária; São Paulo: Cultura Acadêmica, 2014. p. 89-9o.

. Liberdade e Conflito - O confronto dos desejos como fundamento da ideia de

liberdade em Maquiavel, in KRITERION, Belo Horizonte, no 119, Jun./2009, p. 179-19.

. A concepção maquiaveliana de necessidade política. Apresentado na ANPOF 2014, em outubro de 2014, na cidade de Campos do Jordão/SP.

. Lei e violência ou a legitimação política em Maquiavel. In Trans/Form/Ação, Marília, v.34, n.1, p.21-42, 2011.

. Desejo e necessidade e as linguagens da instauração em Maquiavel. Dossiê Estudos Filosóficos. Temas e Matizes, no o6, segundo semestre de 2004.

ARISTÓTELES, Política. Tradução, introdução e comentários de Mário da Gama Kury. Brasília. Ed. Universidade de Brasília, 1997.

BIGNOTTO, Newton. Maquiavel republicano. São Paulo: Loyola, 1991. 

$100,2008$.

A Antropologia Negativa de Maquiavel in: Analytica, Rio de Janeiro, v. 12, n. 2, p. 77Introdução aos Discursos. In: MAQUIAVEL, Nicolau. Discursos sobre a primeira década de Tito Lívio. Tradução MF. São Paulo: Martins Fontes, 2007.

DUVERNOY, J. F. Para conhecer o pensamento de Maquiavel. Porto Alegre: L\&PM, 1974. HEBECHE, Luiz Alberto. A guerra de Maquiavel. Ijuí: UNIJUI, 1988.

KRISTELLER, Paul. Tradição Clássica e Pensamento Renascentista. Trad. Port. Artur Morão. Lisboa: Edições 70, 1979.

LEFORT, C. Le travail de l'oeuvre Machiavel. Paris: Gallimard, 1972. Machiavel: La Dimension Économique du Politique. In Les formes de l'histoire. Paris: Gallimard, 1978.

PLATÃO. A República. Tradução Carlos Alberto Nunes. 3. ed. Belém: EDUFPA, 2000.

SENELLART, Michel. As artes de governar. Do regimen medieval ao conceito de governo. São Paulo: Ed. 34, 2006.

SKINNER, Quentin. Maquiavel. Tradução de Denise Bottmann. Porto Alegre: LM\&P, 2012. . As fundações do pensamento político moderno. Trad. Renato Janine Ribeiro. São Paulo: Cia. das Letras, 1996.

Submissão: 05.10.2017 / Aceite: 08.11.2017 